\title{
THE MEDICAL MANAGEMENT OF INFLAMMATORY BOWEL DISEASE
}

\author{
SURGEON CAPTAIN G J MILTON-THOMPSON, MB, FRCP
}

\author{
Royal Navy Hospital, Haslar
}

Mr. Chairman, Ladies and Gentlemen, firstly I am delighted that the Royal Navy is associated with this symposium and we look forward to increasing cooperation between all three Services, because $I$ think we all have a lot to learn from each other. Secondly, when I am talking about the treatment of Inflammatory Bowel Disease I have to acknowledge my great debt to my former colleagues at St Mark's, particularly Professor John Lennard-Jones and Doctor Basil Morson.

I am not going to tell you exactly how to treat Inflammatory Bowel Disease because, as we have already heard this morning, we do not really know what we are treating. Treatment is empirical and is suppressive but not curative; although we largely use the same methods of treating ulcerative colitis and Crohn's disease the differences in the way we handle these diseases to which $I$ will refer in due course are often based on clinical impressions rather than scientific evidence.

In deciding how to treat Inflammatory Bowel Disease, we first must make a decision about the severity of the condition. I am going to talk primarily about ulcerative colitis, pointing out differences from Crohn's disease. We assess the serverity of the disease by the same criterila as with all other conditions: on the history, physical examination and investigations. Brian Creamer has covered a lot of this so I need not spend too long on it. Clearly we must take a careful history. Are the stools solid or liquid? Is there loss of appetite, loss of weight, or a systemic complication? In examining the patient there are one or two special points I would like to make; does the patient look ill or well? Fever, tachycardia, dehydration, anaemia are all to be looked for. Abdominal tenderness can be a very deceptive thing because patients can often be quite ill with very little abdominal tenderness and hardly any evidence of systemic manifestations. We tend to assume when we first start dealing with Inflammatory Bowel Disease that a patient with Inflammatory Bowel Disease should look emaciated and ill. But certainly in our practice they often look sunprisingly well and yet may have extensive disease, albeit in remission; quite a lot of the sailors that I see (as opposed to the civilians-we have about half and half), may have extensive disease and be entirely fit and well and able to do their job.

The next point I wish to make is about the physical examination because our junior staff when they first arrive from their teaching hospital sometimes forget that examination of a patient with diarrhoea does involve examination of the affected organ. Examination by means of the sigmoidoscope is part of the initial examination.

The results of investigations must be borne in mind before deciding on treatment. There has already been some discussion about the anaemia. Of the plasma proteins, albumin is panticularly relevant when deciding on treatment. I would not presume to say any more on radiology after Dr Herlinger's masterly presentation, 
but I will perhaps add a comment of my own on the matter that came up for discussion, because data from the Central Middlesex and St Mark's emphasizes what has already been said, that the barium enema does under-estimate the extent of the disease. One hundred and three patients were both colonoscoped and had barium enemas; agreement on the extent was present in only half the examinations and the other half showed either more extensive disease or indeed total colitis; it is, of course, the total colitics who we believe to be at risk from cancer in the long term.

Now let me try and be more specific about treatment. Patients with Inflammatory Bowel Disease firstly have a very unpleasant condition, and secondly have a problem that is going to be with them for a very long time. It is for these reasons that I think psychological support is very important. I believe we should treat our patients in clinics designed for the reception and treatment of these patients. We run an Inflammatory Bowel Disease clinic at Haslar, and all patients who have Inflammatory Bowel Disease are appointed to that clinic for follow up. The advantages of this arrangement are that they see one doctor instead of a wide variety, they see a doctor who has some experience in the condition and they not only get better treatment, but also feel much more confident about their disease; I think this is very important.

Dietary measures have always been traditional in English medicine, but there is very little evidence that altering the residue content of the diet is important, except in acute disease, and I am not very impressed with milk withdrawal. Replacement therapy is self evident and I do not really need to go into it in detail, because when patients lose iron, electrolytes, fluid, protein or blood it needs replacing as part of treatment.

Having talked about general measures, let me now remind you that treatment depends on severity, and severity depends both on the extent of the disease and the acuteness of the inflammation. I am going to divide the attack of acute colitis into three groups: mild colitis which is dista], moderately severe colitis which may be left-sided or may by complete and the severe colitic who is in danger of death.

Mild colitis is easy to treat and is much the most common variety. The patient must be encouraged to lead a normal life, and must be encouraged to keep his mind off his bowels. Iron supplements may be necessary but the malinstays of treatment are sulphasalazine and steroids. The St Mark's 'do-it-yourself' rectal enema kit consists of prednisolone 21 -phosphate $5 \mathrm{mg}$ tablets, a bladder syringe and a rubber tube. It happens to be the cheapest mathod for local administration of steroid and also has the advanitage that you can vary the volume and the dose. It is one third of the cost of conventional proprietary enema preparations such as Predsol and Colifoam, but it is not very satisfactory for a young soldier or sailor to carry all that gear around with him and in the Service I am afraid we use the more expensive varieties which are ready to hand. Colifoam is cheaper than Predsol and because a lot of patients complain that they cannot retain socalled retention enemas, the foam variety is useful since it does stay where it is put. There is, of course, absorption through the mucosa and John Lennard-Jones' group recently published some figures showing that you get approximately half the blood level from $20 \mathrm{mg}$ inserted per rectum that you do if given by mouth. 
There is therefore some systemic effect as well as local effect.

Nobody knows how sulphasalazine works but we do know that it is broken down by colonic bacteria into sulfapyridine and 5-amino-salicyclic acid and there has recently been some evidence from Oxford that it is the 5-amino-salicylic acid that is the active principle. It has been suggested that sulfapyridine carries the 5-amino-salicylic acid to the appropriate place, and is no more than a vehicle. Sulphasalazine is an excellent drug both in the acute phase and as maintenance therapy. The commonest problem with it is dyspepsia but substitution of the enteric-coated variety cures their dyspepsia as a rule.

Turning to the moderate colitic, who has a lot of bloody diarrhoea, weight loss and anaemia there is no doubt that they are better off in hospital. They also require replacement therapy as necessary and they usually need oral steroids. We do not use more than $40 \mathrm{mg}$ a day oral Prednisolone because there is some evidence in the literature that a higher dose is of no additional value. We combine this with retention enemas and sulphasalazine if the patient can tolerate it.

Acute fulminating colitis must be managed jointly with the surgeon from the beginning. I think this very important; joint management between physician and surgeon is essential in all serious problems of colitis or Crohn's disease, and surgical advice is very helpful from the beginning. Replacement therapy is very necessary; of course blood and parenteral nutrition is increasingly recognised to be important.

There is argument, and I know of no good data to resolve this, that ACTH is better than Prednisolone. This is a clinical impression; but I prefer to use ACTH in a very ill patient. We use it in a dosage of 80 units daily, reducing as the patient improves. We do not use broad spectrum antibiotics.

Now let us think about maintenance treatment, because most of our colitics and indeed most of our Crohn's disease patients are on maintenance therapy. There is no doubt about the value of sulphasalazine as maintenance treatment. There has been one published trial of bran as maintenance therapy and that showed no benefit. Azathioprine was touched on this morning as maintenance treatment in colitis, and the final conclusion was that it conferred no advantage Steroids have no place in maintenance treatment of ulcerative colitis but there is a strong clinical impression backed up by a little hard data that steroids are of value as maintenance treatment in Crohn's disease. When one has to maintain patients with Crohn's disease on steroids for a long time there are arguments in favour of giving them alternate day doses, but this particularly applies to a child or growing patients. Once they have stopped growing I do not think it is so important, but alternate day doses seem to keep them well and are probably preferable.

The management of anal lesions poses special problems. I am not encroaching on the surgeons' province because physicians would like to think that they could do something about treating anal lesions. Mr Nigel Baker and I looked retrospectively at two hundred patients with anal lesions at St Mark's and at no time did medical treatment appear to influence the course of their disease. Perhaps more important, a number of patients developed new anal lesions at a time when their bowel symptoms were very effectively controlled by medical treatrnent. I am afraid physicians have nothing to offer in the treatment of anal lesions. 